\title{
Adrenal Insufficiency in Australia: Is it Possible that the Use of Lower Dose, Short-Acting Glucocorticoids has Increased the Risk of Adrenal Crises?
}

Authors

Affiliations

\author{
R. L. Rushworth' ${ }^{1}$ D. J. Torpy ${ }^{2}$
}

School of Medicine, Sydney, The University of Notre Dame, Australia, Darlinghurst, Sydney NSW, Australia Endocrine and Metabolic Unit, Royal Adelaide Hospital, University of Adelaide, North Terrace, Adelaide, SA, Australia
Key words

- Addison's disease

- adrenal crisis

glucocorticoid replacement received 07.09 .2014

accepted 18.11.2014

Bibliography

DOI http://dx.doi.org/

10.1055/s-0034-1395680

Published online:

March 4, 2015

Horm Metab Res 2015;

47: 427-432

(c) Georg Thieme Verlag KG

Stuttgart · New York

ISSN 0018-5043

Correspondence

R. L. Rushworth

School of Medicine, Sydney

The University of Notre Dame,

Australia

160 Oxford St.

Darlinghurst

Sydney NSW 2010

Australia

Tel.: +61/2/82044450

Fax: $+61 / 2 / 93577680$

louise.rushworth@nd.edu.au

\section{Abstract}

$\nabla$

Morbidity from adrenal insufficiency (AI) in Australia is poorly described. The objective of this study was to evaluate AI morbidity patterns in adults between 1999/2000 and 2011/2012 using national databases. A descriptive study of hospitalisations for $\mathrm{AI}$ and adrenal crises (AC) in adults and trends in prescriptions for 2 short-acting glucocorticoids (GC) was designed. The setting was the Australian healthcare system. Main outcome measures are the trends in hospitalisation and prescription rates. There were 7378 hospital admissions for treatment of $\mathrm{AI}$ in adults between 1999/00 and 2011/12. Of these, 29.5\% were for an AC. Admission rates for AC increased from 9.5 to 12.4 admissions $/ 10^{6} /$ year $(p<0.05)$. There was a $5.8 \%$ decrease in admission rates for $\mathrm{AI}$ (excluding AC), from 27.0 to $25.5 / 10^{6} /$ year $(p=n s)$. Short-

\section{Introduction}

Adrenal insufficiency (AI) results from many diseases, which impact on hypothalamic-pituitaryadrenal axis function, resulting in partial or complete deficiency of adrenal steroid production. These are usually divided into adrenal causes [primary adrenal insufficiency (PAI) including Addison's disease (AD)] and secondary adrenal insufficiency (SAI), due to failure of adrenocorticotropin (ACTH) secretion resulting from disease or injury to the pituitary gland or hypothalamus, and due to the consequences of exposure to corticosteroid pharmacotherapy (iatrogenic AI). The estimated prevalence of Addison's disease (AD) or PAI varies between 90 and 140 per million in Western countries [1-5] and, although the incidence and prevalence of PAI in Australia is unknown, it is assumed that there are approximately 100 prevalent cases per million. acting GC [hydrocortisone (HCT) and cortisone acetate (CA)] prescription rates increased significantly $\left(\mathrm{p}<0.001\right.$ ) from $3176.1 / 10^{6}$ to $3463.8 / 10^{6}$. Prescription rates for CA decreased by $22.4 \%$ $(\mathrm{p}<0.001)$ but HCT prescription rates increased to $77.1 \%(\mathrm{p}<0.001)$. The increase in AC admission rates was positively correlated with the rise in both the total GC prescription rate $(r=0.63$, $\mathrm{p}<0.05)$ and the HCT prescription rate $(\mathrm{r}=0.74$, $\mathrm{p}<0.01$ ). Over the 13 -year study period, there was a $30.8 \%$ increase in hospitalisation rates for ACs and a concomitant $77.1 \%$ increase in prescribing of HCT. The association between AC events and HCT use and/or reduced effective GC dose is plausibly causal, but confirmatory studies are required before suggesting any change to $\mathrm{GC}$ replacement in AI.
By comparison, SAI is thought to be more common than PAI by a factor of 2:1 [6-8].

Adrenal crises (ACs) are a medical emergency. Symptoms include severe weakness, syncope, abdominal pain, vomiting and confusion and these are accompanied by biochemical abnormalities, which include hyponatraemia, hyperkalaemia, and occasionally hypoglycaemia and hypercalcaemia. They represent a relatively common source of morbidity and hospital admission in patients with $\mathrm{AI}$ (6-10\% annual risk in PAI), and may contribute to reduced life expectancy [9-12]. However, there is little data on long term trends in AC incidence. Intercurrent infectious diseases, especially gastrointestinal illnesses, are common precipitating factors for $\mathrm{AC}$ in treated $\mathrm{AI}$, although $\mathrm{AC}$ can occur without an obvious precipitant.

Adrenal steroid replacement therapy comprises a glucocorticoid (GC) such as short-acting cortisone acetate (CA) or hydrocortisone 
(HCT) (biological activity $8 \mathrm{~h}$ ) or a longer acting GC such as prednisolone/prednisone or dexamethasone (biological activity 13-16 and 36-54 h respectively) and mineralocorticoid replacement therapy is also used in the majority of patients with PAI. Modern recommended daily dosing of GCs is $30-50 \%$ lower than previously favoured, following data revealing that endogenous cortisol production rates are lower than earlier estimates at $9.9 \pm 2.7 \mathrm{mg} /$ day [13]. HCT is generally recommended in reviews, given that long-acting GCs have been associated retrospectively with evidence of mild Cushingoid effects [14] and increased risks of osteoporosis and metabolic problems such as hyperlipidaemia [15-17], and HCT does not require physiological activation, while CA does. Divided daily dosing is also recommended in an effort to more closely mimic the circadian rhythm $[18,19]$, although there are data to suggest that this approach compromises compliance [20]. In addition, cortisol levels are highly variable between individuals taking any of the current HCT schedules [21]. Currently a HCT dose based on $10-12 \mathrm{mg} / \mathrm{m}^{2}$ body surface area, or approximately $15-24 \mathrm{mg}$ daily for adults, in 2 or 3 doses per day is recommended [22]. However, it is possible that finely adjusted HCT will leave some patients transiently deficient of cortisol due to highly variable pharmacokinetics and brief tissue bioactivity. Should these deficient episodes coincide with periods of stress and increased cortisol requirement, an adrenal crisis may eventuate [10].

In the present study, we aimed to examine patterns of hospitalisation and use of selected adrenal steroid replacement therapies in AI patients in Australia using available data sources over a 13-year period.

\section{Materials and Methods}

$\nabla$

All admissions (episodes of care) in Australian hospitals are recorded by each State and Territory Health Department. This de-identified information is reported to the Australian Institute of Health and Welfare (AIHW), which collates the data on the principal diagnosis of each admission [coded according to International Classification of Diseases Version 10 (ICD 10)] [23] and the data are grouped according to the corresponding Australian financial year (July 1-June 30 ). These data are available in the AIHW datacubes and include the following variables: principal diagnosis, age (in 5 year groups), sex, financial year, and number of admissions. For the purposes of this study, we extracted data on all admissions in adults aged 20 years and over between the years 1999/2000 and 2011/2012 inclusive, in which the principal diagnosis was coded as an Addisonian (adrenal) crisis (AC) (E27.2); primary adrenocortical insufficiency (PAI) (E27.1); drug-induced hypoadrenalism (E27.3); other causes and unspecified causes of hypoadrenalism (E27.4); hypopituitarism (E23.0); and post-surgical hypopituitarism (E89.3). Adrenal crises are medical emergencies requiring hospital admission. Clinical features include severe weakness, syncope, abdominal pain, nausea and vomiting, confusion and delirium, hypotension, hyponatraemia, hyperkalaemia, and occasional hypoglycaemia and hypercalcaemia. By comparison, the features of adrenal insufficiency are milder and comprise fatigue, weight loss, postural dizziness, anorexia, abdominal discomfort, and hyponatraemia and hyperkalaemia. To constitute a reason for hospital admission for AI as a principal diagnosis, there would often be a concomitant illness.
Information on the Australian population is available from the Australian Bureau of Statistics (ABS), which publishes data on the population in each census year, and the inter-censal estimates for the intervening years. We extracted population data on each year included in the study by 5 -year age groups and sex. These groups were combined to give the denominator populations for each year of the study.

Data on all pharmaceuticals supplied through the Australian Pharmaceutical Benefits Scheme (PBS) are available from the PBS by financial year and pharmaceutical formulation. We extracted data on all prescriptions for 2 GCs: HCT $(4 \mathrm{mg}$ and $20 \mathrm{mg}$ ); and CA (5 mg and $25 \mathrm{mg}$ ). Prescriptions for prednisolone/ prednisone and dexamethasone were not included, as these formulations are not exclusively prescribed for AI. We also extracted data on prescriptions for the mineralocorticoid, fludrocortisone acetate (FA) ( $0.1 \mathrm{mg}$ ), which is used primarily for PAI. Trends in prescriptions of the selected steroid replacement therapies were analysed for each year of the study period, from $1999 / 2000$ to $2011 / 12$.

Statistical analysis was conducted using the Microsoft Excel (2007, Redmond, Washington: Microsoft) and SPSS-X (IBM SPSS Statistics for Windows, Version 20.0 Armonk, NY: IBM Corp) software packages. To adjust for changes in the underlying prevalence of AI, secondary to changes in the Australian population, admission rates per million population were calculated by dividing the number of admissions for each year by the corresponding population and converting this into a rate per $10^{6}$ population. Prescription rates were calculated in the same way.

A z-score for the difference in 2 proportions was used to assess the significance of the observed difference between the admission and prescription rates between the last year of the study and the base year. Pearson correlation coefficients were calculated to assess the association between admission and the prescription rates. A significance level of $\mathrm{p}<0.05$ was used throughout the analysis.

\section{Results}

$\nabla$

\section{Hospital Admissions}

Over the study period, there were a total of 7378 admissions in adults aged 20 years and over recorded for all causes of AI. The annual number of admissions increased by $38.3 \%$, from 465 in $1999 / 00$ to 643 admissions in 2011/12. This corresponded to a $3.7 \%$ increase in admission rates from 36.6 to $37.9 / 10^{6}$ population/year, which was not significant. The changes in the total number of admissions and the number of admissions by AI category are shown in $\odot$ Table 1.

Adrenal crises comprised 2176 (29.5\%) of the total admissions, corresponding to an average of 167.4 admissions/year ( $\bullet$ Table $\mathbf{1}$ ). The number of admissions for an AC increased substantially (74.4\%) over the study period from 121 admissions in 1999/00 to 211 in $2011 / 12$. There was a significant $(z=-2.4, p<0.05)$ increase of $30.8 \%$ in the corresponding admission rates from 9.5 to 12.4 admissions $/ 10^{6} /$ year ( $\odot$ Fig. 1 ). The majority of the AC admissions were among women (61.1\%). Adults aged 20-39 years comprised one third (33.7\%) of the admissions; $28 \%$ were in those aged 40-59; and the highest proportion (38.2\%) was in patients aged 60 years or more.

There were a total of 5202 admissions for AI, excluding AC, over the study period, corresponding to an annual rate of 400.2 admissions/year. While the annual number of admissions 
Table 1 Admissions and prescriptions for Al by category, 1999/00-2011/12.

\begin{tabular}{|c|c|c|c|c|c|c|}
\hline Category & $\mathbf{n}$ & (\%) & $\begin{array}{l}\text { Admission Rate } / 10^{6} \\
\text { (mean, sd) }\end{array}$ & \% change * & $\begin{array}{l}\text { Admission rate } / 10^{6} \\
2011 / 12\end{array}$ & $\mathbf{p}^{\#}$ \\
\hline All Al & 7378 & 100 & 37.7 (1.9) & 3.7 & 37.9 & NS \\
\hline$A C$ & 2176 & (29.5) & $11.0(1.3)$ & 30.8 & 12.4 & $p<0.05$ \\
\hline Al (excl. AC) & 5202 & (70.5) & $26.7(2.7)$ & -5.8 & 25.5 & NS \\
\hline PAI & 2041 & $(27.7)$ & $10.5(2.0)$ & -36.1 & 8.1 & $p<0.001$ \\
\hline Other adrenal & 1251 & $(17.0)$ & $6.3(1.8)$ & 136.8 & 9.5 & $\mathrm{p}<0.001$ \\
\hline Hypopituitarism & 1575 & $(21.3)$ & $8.2(2.5)$ & -44.1 & 5.2 & $p<0.001$ \\
\hline \multirow[t]{2}{*}{ Drug-induced } & 335 & (4.5) & $1.7(0.5)$ & 159.7 & 2.7 & $\mathrm{p}<0.01$ \\
\hline & & & $\begin{array}{l}\text { Prescription Rate } / 10^{6} \\
\text { (mean, sd) }\end{array}$ & \% change * & $\begin{array}{l}\text { Prescription Rate/ } 10^{6} \\
2011 / 12\end{array}$ & $\mathbf{p}^{\#}$ \\
\hline Total Glucocorticoid & 630,679 & $(100)$ & $3212.5(116.7)$ & 9.1 & 3463.8 & $\mathrm{p}<0.001$ \\
\hline Hydrocortisone & 260,877 & 41.4 & $1315.8(224.0)$ & 77.1 & 1777.4 & $p<0.001$ \\
\hline Cortisone Acetate & 369,802 & 58.6 & $1896.7(128.7)$ & -22.4 & 1686.4 & $p<0.001$ \\
\hline Fludrocortisone & 232,255 & $(100)$ & $1177.7(152.6)$ & 40.4 & 1592.7 & $p<0.001$ \\
\hline
\end{tabular}

* Rate difference between final year and the base year as a percentage of the base year

\# Significance of the difference between the admission/prescription rates, 1999/00 and 2011/12

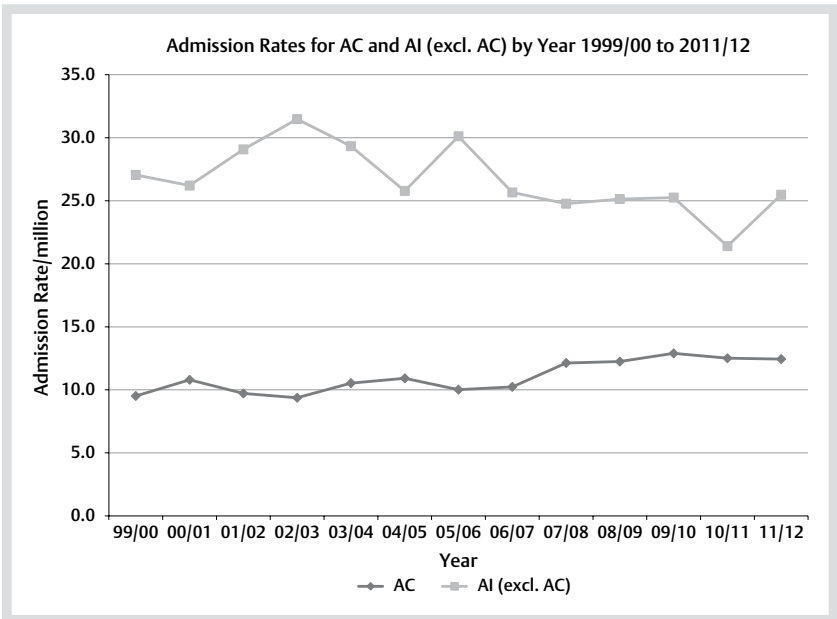

Fig. 1 Admission rates for AC and Al (excluding AC) by Year, 1999/00 to 2011/12.

increased 25.6\% over the base year, from 344 in 1999/00 to 432 in $2011 / 12$, this corresponded to an actual (5.8\%) decrease in admission rates from 27.0 to $25.5 / 10^{6} /$ year, which was not significant ( $\odot$ Fig. 1). Of these, PAI (E27.1) admissions comprised the largest category, with a total of 2041 admissions recorded for the study period, corresponding to an average rate of 157.0 admissions/year. The majority of these were among women (62.1\%). One third (31.0\%) of the admissions were in the youngest age group, $34.0 \%$ were aged between 40 and 59 years and $35.0 \%$ were in the oldest group. The annual number of PAI admissions decreased $14.8 \%$ over the study period from 162 in $1999 / 00$ to 138 in $2011 / 12$, corresponding to a significant $(z=3.9$, $\mathrm{p}<0.001) 36.1 \%$ reduction in admission rates from 12.7 to $8.1 / 10^{6} /$ year.

Admissions in the category of "other causes and unspecified causes of hypoadrenalism (E27.4)" accounted for $17.0 \%$ of the total, corresponding to an annual rate of 96.2 admissions/year ( Table 1). Nearly two-thirds (65.7\%) of these admissions were in women and half (51.5\%) were in patients aged 60 years or more. Only $16.3 \%$ were recorded for the youngest age category and the remainder (32.2\%) were in those aged $40-59$ years. The number of admissions per year for this AI category increased 3-fold over the study period, from 51 admissions in 1999/00 to 161 admissions in 2011/12. These corresponded to a significant $(\mathrm{z}=-5.5, \mathrm{p}<0.001) 136.8 \%$ increase in admission rates, from $4.0 / 10^{6}$ to $9.5 / 10^{6} /$ year.

In contrast to the number of admissions for primary causes of hypoadrenalism, there were fewer $(1575,21.3 \%$ of the total) admissions for the principal diagnosis of hypopituitarism (hypopituitarism or post-procedural hypopituitarism) ( $\odot$ Table 1). These consisted of 1287 (81.7\%) admissions for hypopituitarism and the remainder $(288,18.3 \%)$ were for post-procedural hypopituitarism. In contrast to the female preponderance in PAI, admission for the total hypopituitarism group was more common among men (68.4\%). The age group 40-59 years had the most admissions for hypopituitarism (42.4\%) followed by the oldest group (34.5\%) and the youngest patients had the lowest number $(23.0 \%)$. There was a $25.4 \%$ decrease in the number of admissions for hypopituitarism, which corresponded to a significant $(\mathrm{z}=4.2, \mathrm{p}<0.001) 44.1 \%$ reduction in hypopituitarism admission rates from $9.3 / 10^{6} /$ year to $5.2 / 10^{6} /$ year.

By comparison, there were fewer $(335,4.5 \%$ of the total) admissions for "drug-induced hypoadrenalism (E27.3)". Of these, $60.0 \%$ were in women. The majority were among those patients aged 60 years or over $(62.4 \%)$, while $28.1 \%$ were in patients aged 40-59 years and (9.6\%) were for those aged 20-39 years. Although admissions for this category of hypoadrenalism were rare, there was an increase over the study period from 13 admissions in 1999/00 to 45 admissions in 2011/12. This corresponded to a significant $(\mathrm{z}=-3.2, \mathrm{p}<0.01) 159.7 \%$ increase in admission rates between the first and last years of the study, from $1.0 / 10^{6}$ to $2.7 / 10^{6} /$ year.

\section{Pharmaceutical prescriptions}

Prescriptions for the combined GCs (HCT and CA) increased $45.4 \%$ from 40399 prescriptions in $1999 / 2000$ to 58730 in 2011/12 ( Table 1). These corresponded to prescription rates of $3176.1 / 10^{6} /$ year and $3463.8 / 10^{6} /$ year respectively, or a significant $(\mathrm{z}=-13.4, \mathrm{p}<0.001) 9.1 \%$ increase ( $\odot$ Fig. 2 ).

Of the 2 GCs considered in this study, CA was prescribed more frequently than HCT for the majority of the study period ( $\bullet$ Fig. 2) and the total number of prescriptions for CA increased slightly (3.5\%) from 27635 to 28594 prescriptions over this time. However, after adjusting for the increases in the population, the pre- 
scription rates decreased from $2172.6 / 10^{6} /$ year to $1686.4 / 10^{6} /$ year, corresponding to a significant $(\mathrm{z}=30.1, \mathrm{p}<0.001)$ reduction of $22.4 \%$ (० Fig. 2).

By comparison, there was a very substantial increase $(136.1 \%)$ in the total number of HCT prescriptions from 12764 in 1999/2000 to 30136 prescriptions in $2011 / 12$. The corresponding rates were $1003.5 / 10^{6} /$ year and $1777.4 / 10^{6} /$ year respectively, representing a significant $(z=-54.9, p<0.001)$ increase of $77.1 \%$, after adjustment for population increases ( $\bullet$ Fig. $\mathbf{2}$ ).

In addition, there was a considerable increase $(87.2 \%)$ in the number of prescriptions for FA over the study, from 14428 in $1999 / 2000$ to 27004 in 2011/12. There was a particularly marked increase in FA prescriptions in the latter part of the study, where the prescriptions rose from 18115 in 2009/10 to 24041 in 2010/11 to reach 27004 in 2011/12. The FA prescription rate was 1134.3 in $1999 / 2000$ and $1592.7 / 10^{6} /$ year in $2011 / 12$, corresponding to a significant $(z=-33.1, p<0.001)$ increase of $40.4 \%$ in the prescription rates.

\section{Hospital admissions and pharmaceutical prescriptions}

The increase in AC admission rates over the study period was positively correlated with the observed rise in the combined GC prescription rate $(r=0.63, p<0.05)$ ( $\odot$ Fig. 3 ). The AC admission rates were also positively correlated with the HCT prescription rates $(r=0.74, p<0.01)$ but were negatively correlated $(-0.71$,

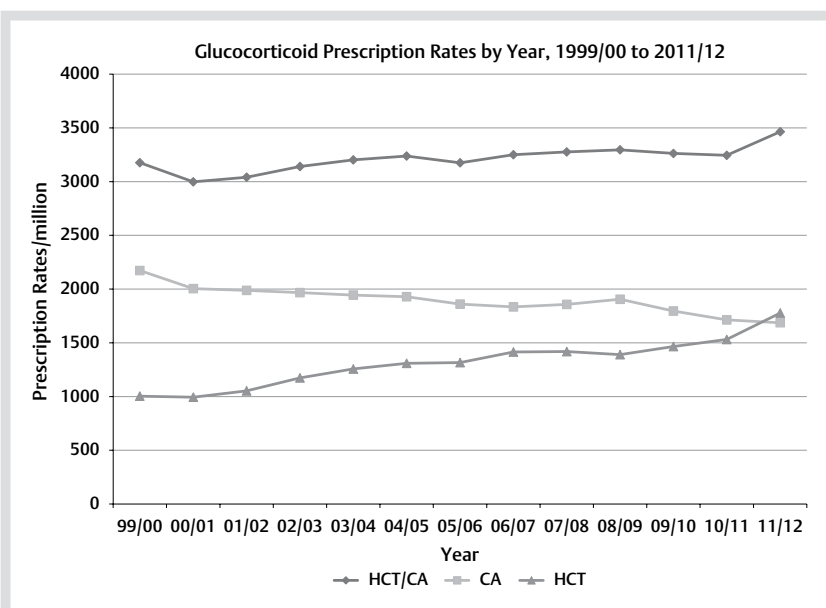

Fig. 2 Glucocorticoid Prescription Rates by Year 1999/00 to 2011/12.

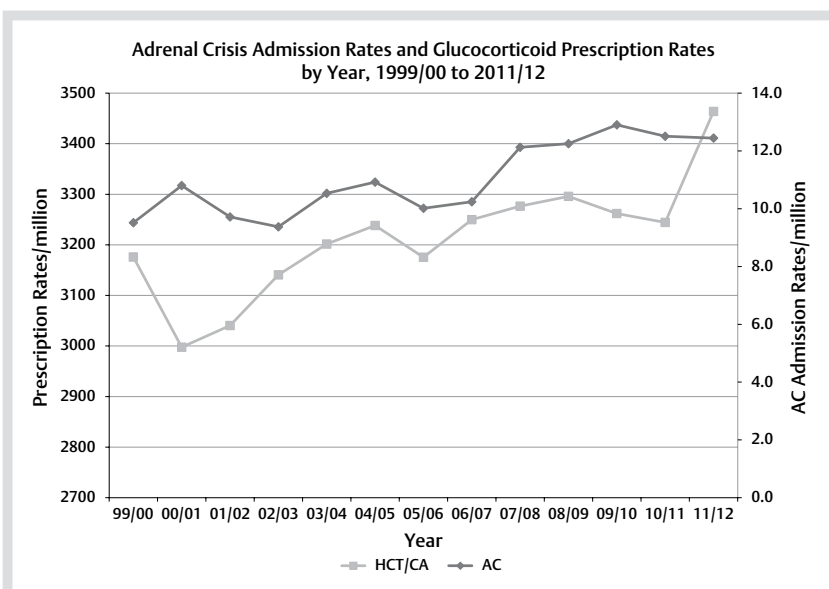

Fig. 3 Adrenal Crisis Admission Rates and Glucocorticoid Prescription Rates by Year $1999 / 00$ to 2011/12. $\mathrm{p}<0.01$ ) with the change in CA prescription rates and were not significantly correlated with the change in FA prescription rates. By comparison, the change in the $\mathrm{AI}$ (non-AC) admission rate was not significantly correlated with the change in the total GC, HCT, CA, or FA prescription rates.

\section{Discussion \\ $\nabla$}

The results of this investigation provide some new insights into the epidemiology and utilisation of health services by adult patients with hypoadrenalism in Australia. The present study demonstrated that, while there was a small increase (3.7\%) in the admission rates for all causes of AI over the study period, this was comprised of a $5.8 \%$ reduction in admission rates for AI (excluding AC) and a substantial (30.8\%) increase in admission rates for an $\mathrm{AC}$. Within the category of $\mathrm{AI}$ (excluding $\mathrm{AC}$ ) there was a reduction in admission rates for both PAI and hypopituitarism (36.1 and $44.1 \%$, respectively). The remaining admissions consisted of an increasing number of patients classified as having "other causes and unspecified causes of hypoadrenalism" and a small number of patients with "drug induced hypoadrenalism".

The reasons for the changing pattern of admissions for AC relative to $\mathrm{AI}$ are unclear but they may be due to changes in the presentation of $\mathrm{AI}$ to the more life threatening AC, which is characterised by hypotension and electrolyte disturbances. Disturbingly, the increased rates of admission for AC (but not the rates of $\mathrm{AI}$ excluding $\mathrm{AC}$ ) were significantly correlated with the increased prescription rates of both GCs combined, in addition to the prescription rates of the short-acting GC hydrocortisone, during a time when the use of lower dose, short-acting GCs was recommended. Specific programs to increase clinician's awareness of AI, and AC in particular, have not been conducted in Australia and for this reason it is unlikely that an increased understanding of AI, which could be reflected in a greater likelihood to diagnose symptomatic AI as an AC, would account for the changes in $\mathrm{AC}$ incidence that were observed in this study. Irrespective of the type of GC replacement therapy, the mainstays of AC prevention involve the use of stress doses with illness, parenteral glucocorticoids (GC) and hospitalisation when required, and a MedicAlert or similar identification to indicate steroid dependence to medical attendants [22].

Although AI is rare in Australia, the results of the present study indicate that there is a disproportionate utilisation of hospital services by these patients. In 2011/12, there were 126.4 admissions for a principal diagnosis of AI per 1000 presumed cases, corresponding to more than $10 \%$ of this estimated total caseload. This suggests that a proportion of patients required hospital admission for management of symptomatic AI, either due to problems with stress management or due to underlying problems with intercurrent illness. There are a number of factors such as co-morbidities $[12,24,25]$ and a predisposition to complications such as bacterial infections [25-27], which may result in patients with $\mathrm{AI}$ requiring greater levels of hospital care. In addition, a number of studies have shown that some patients with AI have difficulties managing their disease during times of illness and injury, necessitating hospital care for patients who may have been able to be managed successfully at home $[10,28]$. The incidence and prevalence of AI in Australia are unknown but we are unaware of any evidence suggesting a change in the incidence of $\mathrm{AI}$ in this country, which might explain the rise in $\mathrm{AC}$ 
rates. It is assumed that Australia has similar prevalence rates to those estimated for the US [29] and the UK [3], as populations in Scandinavia and Northern Europe $[5,30]$ have a greater propensity to autoimmune disease than other groups. In addition, some published prevalence estimates include patients whose $A D$ is a result of tuberculous adrenal failure [3], which is not a feature of the current Australian experience. Further, while HIV infection may play an increasing role in the aetiology of $A D$ in some countries, this is unlikely to feature as part of the Australian AD population [31]. Autoimmune disease is considered to be the main aetiological factor in the development of $\mathrm{AD}$ in Australia, as it is in a number of other countries $[5,29,30,32]$ and, as autoimmune disease is more common in women than men, it is assumed that women are more often affected by $\mathrm{AD}$ [33]. In this study, we found that men represented approximately $40 \%$ of the total patient admissions, a higher proportion than was expected but consistent with the male/female ratio seen in a Swedish study [33].

We observed significant increases in prescription rates for GCs and FA over the study, which may suggest that the background prevalence of $A D$ is greater than the $100 /$ million population that is accepted as the most likely estimate of prevalence in Australia. However, it is likely that the observed increase in the prescription rates for FA may be unrelated to changes in the background prevalence of $\mathrm{AD}$ in the population, as this change may be a reflection of the increasing use of this formulation in the treatment of postural hypotension, especially in the elderly [34]. With the exception of the last year of the study, in which the number of prescriptions for HCT exceeded those for CA for the first time (28594 prescriptions in 2011/12 compared to 30136 for hydrocortisone), CA was the more frequently prescribed GC, although the rate declined $22.4 \%$ over the duration of the study. By comparison, the substantial increase $(77.1 \%)$ in the HCT prescription rate, most probably reflected clinicians' responses to the recommendation that HCT is the preferred GC to manage adrenal failure [22]. CA has been available since shortly after its isolation and initial clinical use in 1948, with HCT and synthetic GCs becoming available more recently. The reason for the comparatively high rate of CA prescribing is, therefore, uncertain. Patient compliance and preferences may play some role in explaining this apparent anomaly, as HCT is usually recommended in at least 2 but often 3 doses per day which, although accepted by patients in clinical trials, may not be an acceptable regimen for some patients or may reduce medication adherence $[19,20]$.

In this analysis, we used data from 2 national administrative datasets. These data provide a wealth of information on aspects of utilisation of health services, including trends over time but they have some limitations. Hospitalisation data provide some information on episodes of care, including the principal diagnosis of the patient, but they are not able to identify the hospital utilisation of individual patients and, therefore, cannot differentiate multiple admissions for the same individual vs. single admissions for different individuals. In addition, there may be inaccuracies in coding and it is possible that some cases of AC, for example, may be coded as other problems that may have precipitated the crisis such as infections or gastroenteritis. There may also be some variability among clinicians with regards to the diagnostic criteria for classification of an AC, as opposed to symptomatic AI. Further, these data cannot include information on patients who have a fatal AC outside the hospital setting and while these can occur, national mortality statistics for deaths due to adrenal diseases have not changed over recent years. Similarly, pharmaceutical prescription data do not enable the identification of individual treatment histories and do not include patient diagnosis, so we were unable to differentiate prescriptions for PAI from secondary (pituitary) causes or FA prescriptions to treat postural hypotension from those used to treat AI. Nor do these prescription data enable the estimation of dose, administration regimen, or the relationship between treatment type and $\mathrm{AC}$ as they are only made available in aggregate the form. However, we believe that these issues are important and that further research may be warranted.

Over 13 years, there has been a marked increase in the rates of ACs, a life-threatening problem that has been estimated in some studies to have an annual risk in AD of between 6 to 10\% [11]. Increased HCT prescribing in Australia corresponded with a period where HCT and, to a lesser extent the similar short acting GC, CA, have been advocated in lower doses in AI. Although we were not able to examine doses of GC used or determine that all of the increased HCT prescribing relates to AI, we suggest that there may be an association between $\mathrm{AC}$ events and the increasing use of HCT, probably given in lower doses than in the past. This association is plausible but requires further validation and detailed investigation prior to altering treatment guidelines.

\section{Acknowledgements}

$\nabla$

We thank the Addison's Association of Australia for an unrestricted grant to facilitate studies on the epidemiology of Addison's disease and its complications.

\section{Conflict of Interest}

$\nabla$

The authors declare that they have no conflicts of interest that could be perceived as prejudicing the impartiality of the research reported.

\section{References}

1 Mason AS, Meade TW, Lee JA, Morris JN. Epidemiological and clinical picture of Addison's disease. Lancet 1968; 2: 744-747

2 Kong MF, Jeffcoate W. Eighty-six cases of Addison's disease. Clin Endocrinol (Oxf) 1994; 41: 757-761

3 Willis AC, Vince FP. The prevalence of Addison's disease in Coventry, UK. Postgrad Med J 1997; 73: 286-288

4 Laureti S, Vecchi L, Santeusanio F, Falorni A. Is the prevalence of Addison's disease underestimated? J Clin Endocrinol Metab 1999; 84: 1762

5 Løvås $K$, Husebye ES. High prevalence and increasing incidence of Addison's disease in western Norway. Clin Endocrinol (Oxf) 2002; 56: 787-791

6 Regal M, Páramo C, Sierra SM, Garcia-Mayor RV. Prevalence and incidence of hypopituitarism in an adult Caucasian population in northwestern Spain. Clin Endocrinol 2001; 55: 735-740

7 Arlt W, Allolio B. Adrenal insufficiency. Lancet 2003; 361: 1881-1893

8 Fernandez-Rodriguez E, Lopez-Raton M, Andujar P, Martinez-Silva IM, Cadarso-Suarez C, Casanueva FF, Bernabeu I. Epidemiology, mortality rate and survival in a homogeneous population of hypopituitary patients. Clin Endocrinol 2013; 78: 278-284

9 Erichsen MM, Løvås K, Fougner KJ, Svartberg J, Hauge ER, Bollerslev J, Berg JP, Mella B, Husebye ES. Normal overall mortality rate in Addison's disease, but young patients are at risk of premature death. Eur J Endocrinol 2009; 160: 233-237

10 White $K$, Arlt W. Adrenal crisis in treated Addison's disease: A predictable but under-managed event. Eur J Endocrinol 2010; 162: 115-120 
11 Hahner S, Loeffler M, Bleicken B, Drechsler C, Milovanovic D, Fassnacht $M$, Ventz $M$, Quinkler M, Allolio B. Epidemiology of adrenal crisis in chronic adrenal insufficiency: the need for new prevention strategies. Eur J Endocrinol 2010; 162: 597-602

12 Meyer G, Neumann K, Badenhoop K, Linder R. Increasing prevalence of Addison's disease in German females: health insurance data 20082012. Eur J Endocrinol 2014; 170: 367-373

13 Esteban NV, Loughlin T, Yergey AL, Zawadzki JK, Booth JD, Winterer $J C$, Loriaux DL. Daily cortisol production rate in man determined by stable isotope dilution/mass spectrometry. J Clin Endocrinol Metab 1991; 72: 39-45

14 Di Dalmazi G, Vicennati V, Rinaldi E, Morselli-Labate A, Giampalma E, Mosconi C, Pagotto $U$, Pasquali $R$. Progressively increased patterns of subclinical cortisol hypersecretion in adrenal incidentalomas differently predict major metabolic and cardiovascular outcomes: A large cross-sectional study. Eur J Endocrinol 2012; 166: 669-677

15 Løvås $K$, Gjesdal CG, Christensen $M$, Wolff AB, Almås B, Svartberg J, Fougner KJ, Syversen U, Bollerslev J, Falch JA, Hunt PJ, Chatterjee VK, Husebye ES. Glucocorticoid replacement therapy and pharmacogenetics in Addison's disease: effects on bone. Eur J Endocrinol 2009; 160: 993-1002

16 Björnsdottir S, Sääf M, Bensing S, Kämpe O, Michaëlsson K, Ludvigsson $J F$. Risk of hip fracture in Addison's disease: a population-based cohort study. J Intern Med 2011; 270: 187-195

17 Filipsson H, Monson JP, Koltowska-Häggström M, Mattsson A, Johannsson $G$. The impact of glucocorticoid replacement regimens on metabolic outcome and comorbidity in hypopituitary patients. J Clin Endocrinol Metab 2006; 91: 3954-3961

18 Hahner S, Loeffler M, Fassnacht M, Weismann D, Koschker A, Quinkler $M$, Decker 0 , Arlt $W$, Allolio B. Impaired subjective health status in 256 patients with adrenal insufficiency on standard therapy based on cross-sectional analysis. J Clin Endocrinol Metab. 2007; 92: 3912-3922

19 Mah PM, Jenkins RC, Rostami-Hodjegan A, Newell-Price J, Doane A, Ibbotson V, Tucker GT, Ross RJ. Weight-related dosing, timing and monitoring hydrocortisone replacement therapy in patients with adrenal insufficiency. Clin Endocrinol (Oxf) 2004; 61: 367-375

20 Forss M, Batcheller G, Skrtic S, Johannsson G. Current practice of glucocorticoid replacement therapy and patient-perceived health outcomes in adrenal insufficiency - a worldwide patient survey. BMC Endocr Disord 2012; 12: 8

21 Simon N, Castinetti F, Ouliac F, Lesavre N, Brue T, Oliver C. Pharmacokinetic evidence for suboptimal treatment of adrenal insufficiency with currently available hydrocortisone tablets. Clin Pharmacokinet 2010; 49: 455-463
22 Nieman $L K$. Treatment of adrenal insufficiency in adults. Up To Date 2013; Online subscription; www.uptodate.com

23 World Health Organisation. International Statistical Classification of Diseases and Related Health Problems, $10^{\text {th }}$ Revision (ICD-10). Geneva: WHO, 1992

24 Bergthorsdottir R, Leonsson-Zachrisson M, Odén A, Johannsson G. Premature mortality in patients with Addison's disease: A populationbased study. J Clin Endocrinol Metab 2006; 91: 4849-4853

25 Leelarathna L, Breen L, Powrie JK, Thomas SM, Guzder R, McGowan B, Carroll PV. Co-morbidities, management and clinical outcome of autoimmune Addison's disease. Endocrine 2010; 38: 113-117

26 Smans LCCI, Souverein PC, Leufkens HGM, Hoepelman AIM, Zelissen $P M J$. Increased use of antimicrobial agents and hospital admission for infections in patients with primary adrenal insufficiency: A cohort study. Eur J Endocrinol 2013; 168: 609-614

27 Rushworth RL, Torpy DJ. A descriptive study of adrenal crises in adults with adrenal insufficiency: increased risk with age and in those with bacterial infections. BMC Endocr Disord 2014; 14: 79

28 Repping-Wuts HJ, Stikkelbroeck NM, Noordzij A, Kerstens M, Hermus AR A glucocorticoid education group meeting: an effective strategy for improving self-management to prevent adrenal crisis. Eur J Endocrinol 2013; 169: 17-22

29 Jacobson DL, Gange SJ, Rose NR, Graham NM. Epidemiology and estimated population burden of selected autoimmune diseases in the United States. Clin Immunol Immunopathol 1997; 84: 223-243

30 Betterle C, Scarpa R, Garelli S, Morlin L, Lazzarotto F, Presotto F, Coco G, Masiero S, Parolo A, Albergoni MP, Favero R, Barollo S, Salvà M, Basso D, Chen S, Rees Smith B, Furmaniak J, Mantero F. Addison's disease: a survey on 633 patients in Padova. Eur J Endocrinol 2013; 169: 773-784

31 George MM, Bhangoo A. Human immune deficiency virus (HIV) infection and the hypothalamic pituitary adrenal axis. Rev Endocr Metab Disord 2013; 14: 105-112

32 Falorni A, Minarelli V, Morelli S. Therapy of adrenal insufficiency: an update. Endocrine 2013; 34: 514-528

33 Erichsen MM, Løvås K, Skinningsrud B, Wolff AB, Undlien DE, Svartberg J, Fougner KJ, Berg TJ, Bollerslev J, Mella B, Carlson JA, Erlich H, Husebye ES. Clinical, immunological, and genetic features of autoimmune primary adrenal insufficiency: observations from a Norwegian registry. J Clin Endocrinol Metab 2009; 94: 4882-4890

34 Arnold AC, Shibao C. Current concepts in orthostatic hypotension management. Curr Hypertens Rep 2013; 15: 304-312 